\title{
Comparative Analysis of Private Sector Hospital Performance Before and After Implementation of TQM and
} $5 s$

\author{
Balasubramanian Mahadevan \\ Depterment of Hospital Administration, Raptakos, Brett \& Co. LTD, Mumbai, India
}

Email address:

mbalas2001@hotmail.com, mbalas2001@yahoo.co.in

\section{To cite this article:}

Balasubramanian Mahadevan. Comparative Analysis of Private Sector Hospital Performance Before and After Implementation of TQM and 5s. Science Journal of Public Health. Vol. 8, No. 4, 2020, pp. 92-98. doi: 10.11648/j.sjph.20200804.11

Received: April 15, 2020; Accepted: May 13, 2020; Published: June 9, 2020

\begin{abstract}
The research paper has been published to develop a brief idea regarding the implementation of TQM\&5s and its result on the hospitals performance including patient satisfaction. For the betterment of this study four Leading Tertiary Care hospitals have been considered. Again, the model of SERVQUAL is taken to assess the clinical quality and Patient satisfaction as well. In this project, the role of the SERVQUAL model is well discussed which gives a clear idea on measuring customer satisfaction. As a result of this study, it has been found that quality needs to be measured at several stages such as unit level, organization level, and individual level. Though the positive impact on the implementation of the SERVQUAL model has been discussed in this paper, there are also some barriers that need to be solved by the hospitals to properly implement TQM\&5s.
\end{abstract}

Keywords: TQM, Total Quality Management, SERVQUAL Model, Healthcare, Measurements

\section{TQM Definition}

"Total quality management (TQM)" is one of the crucial aspects even in the hospital or health care sector due to its need and demand among the patients. Due to various reasons such as rules and regulations of any official body, needs of customers, customer satisfaction, superior management quality and more, the rise of the concept of TQM could be seen. Along with this, again, the fundamental concept of TQM could be understood by factors such as improving the management quality within a hospital, "managing clinical quality", and implementation of strategic plans related to quality management, benchmarking, and more. Again, the four factors of the concept behind the application of TQM in healthcare are empowering, developing motivation, multidisciplinary approach, and adaptation.

\section{Theoretical Background \& Quality}

In this study, the implementation of the TQM concept will be evaluated, as the background of this management theory also indicates the possibilities and scope after the implementation process [3] Though the concept of TQM is now new, the application and its results are presented to prove the efficiency that the TQM could bring to any hospital. Therefore, quality and theories will be well developed and applied to some chosen hospital for the betterment of this study. From the background study of this study, it is clear that there are few reasons behind the rapid growth of the implementation of TQM, in healthcare organizations. These reasons are high cost and low value from service, technology dependence, the pressure to reduce the cost and improving the quality because of customer needs and rules from government bodies, and satisfaction for customers [2]. This demand for high quality from public and government hospitals are the major reasons behind the growth of TQM.

The research study from past years gives a clear idea regarding the metrics and importance of the TQM study. In the year of 2000, Theodorakis Oglou has made research which indicates various statements. The first is regarding the implementation of TQM, where the author has mentioned that the implementation of TQM in the healthcare industry is very rare. Again, the lack of monitoring of the data and 
information in this sector is another reason because TQM requires a modern technological application.

\section{Select Studies}

In this research paper, the implementation of TQM\&5S has been considered especially for four hospitals. These four hospitals on which the study will be based on, are listed below:

1) Breach candy hospital

2) Saifee Hospital

3) Bhatia Hospital

4) Hinduja health care
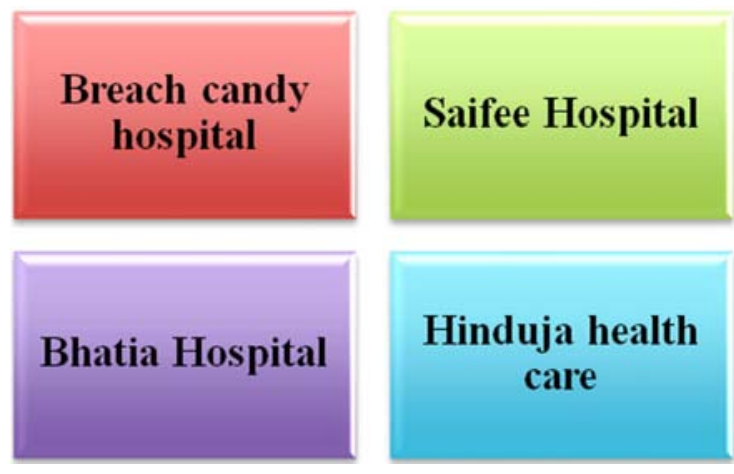

(Source: Self- created).

Figure 1. List of hospitals considered for TQM\&5S.

The selected health-care organizations are based on the region of India, where the healthcare industry is massive [6] It is estimated that this industry will reach USD 133.44 trillion by the end of 2022. Therefore the competition is huge as well. Along with this, other factors such as reducing the cost, improving the clinical quality and rules from the government authorities are forcing these hospitals to give special attention to the concept of TQM\&5S. In this study, the implementation will be discussed and also its after-effects on the clinical quality of hospitals. Therefore, by considering these studies, a in -detailed evaluation could be done based on the present scenario of these hospitals and components of TQM\&5S.

\section{Measuring Service Quality}

The quality assessment is one of the most beneficial parts of this study, where various dimensions and metrics will be considered to understand the service quality, customer satisfaction of the chosen hospitals [4] The study will be done by considering customer satisfaction and clinical quality as a separate part of TQM\&5S. For the betterment of this study, the clinical quality will be chosen as a long term measurable tool, whereas the customer's needs will be taken as short term value. It is also important to notice that both events are dependent on each other, therefore the measurement must be done by separating two elements of TQM measurement. Again, the traditional method of measuring the customer's satisfaction was based on the mood, which was difficult to observe. In this study, modern techniques and models such as SERVQUAL will be considered for evaluating the quality and customer satisfaction in the context of TQM\&5S.

Questionnaire is considered in this study to understand the customer reaction regarding this service offered by breach candy hospital. For this Questionnaire, a sampling size of 63 has been selected to get the most suitable result regarding the quality and customer support for the Breach candy hospital \&other Hospitals.

Q1. How do you rate the services of Breach candy hospital?

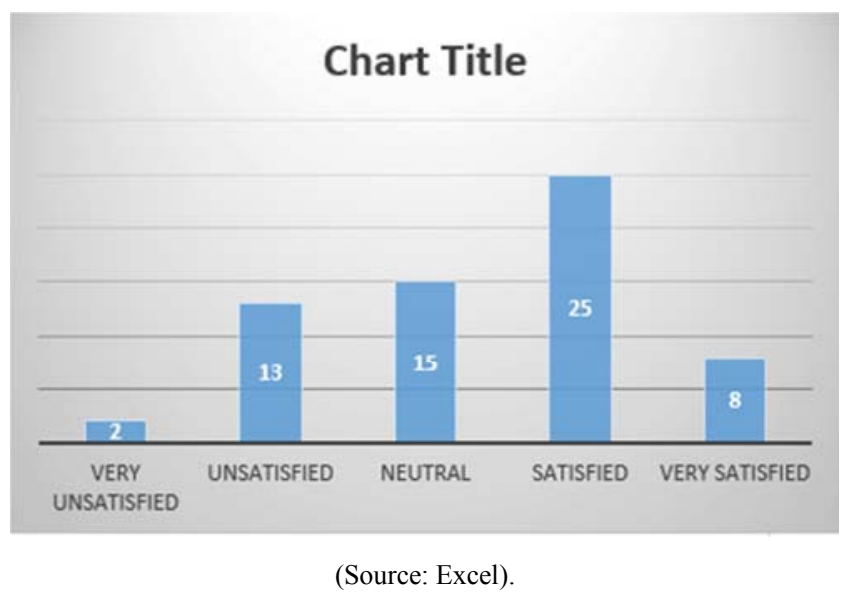

Figure 2. Bar chart for the questionnaire.

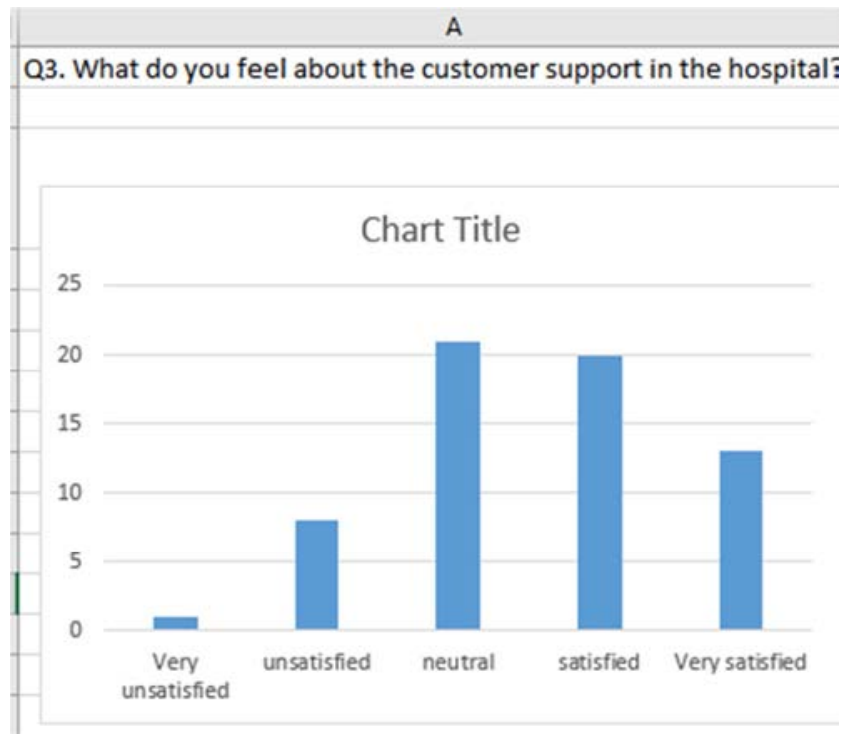

(Source: Excel).

Figure 3. Bar chart for the questionnaire.

\section{Results After TQM Implementation on Breach Candy Hospital}

In this case, four hospitals were analyzed with the help of SERVQUAL model. The results are presented in the form of charts which are discussed here as well. After implementing different criteria of the hospitals these above results are generated accordingly with graph. 
Remaining questionnaire and graphs are also attached in this paper.

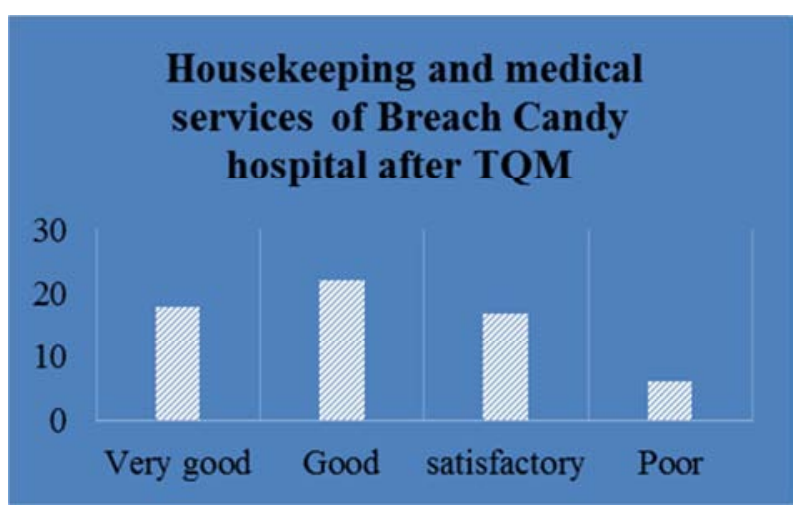

(Source: Excel).

Figure 4. Bar chart for the questionnaire.

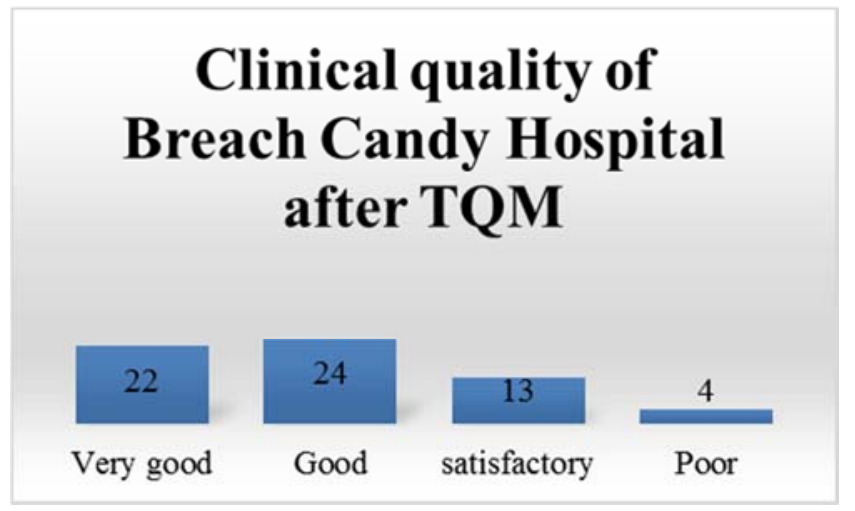

(Source: Excel).

Figure 5. Bar chart for the questionnaire.

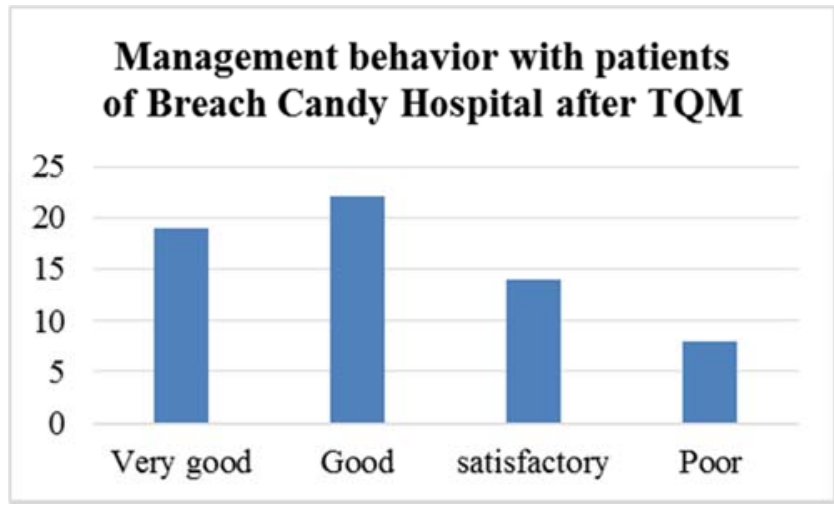

(Source: Excel).

Figure 6. Bar chart for the questionnaire.

\section{SERVQUAL Model}

Due to the lack of management and strategic plan, it was difficult to measure the customer's satisfaction [5]. Therefore the scope of a new method was required, as a result, the "SERVQUAL method" was discovered. As per this model, the customer's satisfaction was considered as the difference between the expectation and actual scenario in terms of the clinical quality of a hospital. Again, this measurement is considered to perform at three different levels to get a proper and reasonable data and information regarding the performance of any hospital in the context of quality assessment. Organizational, individual-level and unit levels must need to measure in order to get a brief idea of monitoring the performance. Along with quality measurement, two important methods of identifying performance plays a crucial role. Constant inquiries to the patients and questionnaire models are considered in this model (Abadi et al. 2018). Again, due to the gap between expectation and actual result from the quality performance, the method discusses several factors such as:

1) Reliability

2) Responsiveness

3) Communication

4) Credibility

5) Security

\section{SERVQUAL Model- Barriers}

Though the model was appropriate for the measurement of quality in hospitals such as Breach candy hospital, Saiff Hospital, Bhatia Hospital, and Hinduja health care, this model also has some barriers as well which prevents the model to get an efficient result. One of the most crucial challenges or barriers in this model is related to the conflict between the two bodies of the hospital such as office staff and medical staff because both units work separately [7]

Due to this reason communication becomes a major issue that is highly responsible for the conflict occurred between these two parties of a hospital. Again, the improper structure of a healthcare organization is also responsible for this scenario, as doctors consider their work as an individual task that has less engagement from the authority of the hospital. In the context of quality assessment and measuring the customer's satisfaction, customer service also plays a crucial role. This helps in understanding the inquiries and reaction after the service is offered. Therefore these four hospitals taken needs to implement a service where proper customer support will be available.

\section{SERVQUAL Model - Challenges}

There are some barriers that can be faced by hospital in the implementation of SERVQUAL Model in their organizational structure. The healthcare organization may face some resistance from their employees as well as their patients for using this model. The limited commitment, interest diffusion as well as the hospital structure may be the major barriers and resistances to the implementation of this model. The regulations as well as the scrutiny that are the outside matters of doctors are the negative factor to medical care for doctors. The possible resistance or barriers that can be faced by hospitals in implementing the SERVQUAL Model in their organizational structure are mainly resistances from a physician. The implementation of this model in the 
hospital structure by reducing the resistance from doctor and physicians have become important. There is a possibility of doctors facing fear regarding the degradation of their healthcare quality due to the implementation of this model in the hospital structure. Lack of resources, as well as improper maintenance, also adds to the resistances and barriers of implementation of this model in their hospital structure in addition to the problems regarding the availability of drugs and medicines. Unreasonable attendants and patients also add to the resisting factors [8]

\section{SERVQUAL Model - Implementation}

Implementation of the SERVQUAL Model requires some of the steps mentioned below:

1 Identification of the issue or problem that is faced by the healthcare organization

2 Setting up of standards and criteria is the second step that needs to be followed for implementation of this model in the hospital structure

3 Data collection based on observations will be the next step to be followed

4 Comparison of performance with the standards and criteria are the fourth step for the implementation

Again, 5s activities are also considered. By application $5 \mathrm{~s}$, the hospital and quality management will be improved for hospitals. Activities that have been considered for the implementation process are: [Referred to Appendix 1]

"i") Sort

"ii") Set

"iii") Shine

"iv") Standardize

"v") Sustain

In case of implementation of this model, it is also important to evaluate the key strength of the hospital. For example the chosen hospital Saifee hospital also have some key strengths which are listed below:

a) Multi storey organization with more than 250 numbers of bed in the hospital

b) Health care organization is also an ISO certified as well.

c) Technology and equipment of this hospital is also up to date with modern technology.

d) Robotic surgical system is also included in this hospital.

ISO 9000 is also a necessary set of guidelines that is also applied in this study to maintain the work under government rules and regulations. These are the steps that need to be followed by the hospital in the implementation of the SERVQUAL model in the structure of the healthcare organization. [Appendix 2]

\section{Results}

Four chosen hospitals are taken into consideration for the implementation of TQM\&5s. In this case, the ranking of these hospitals are also made based on certain factors, such as cleanliness, staff to nurse ratio, bed occupancy. After analyzing the results, the results indicate that the Breach
Candy Hospital has the better ranking as compared to other three hospitals. Therefore the implementation of TQM\&5s has benefited Breach candy hospital the most. It has been also reviewed through the graphs that the bed occupancy of Breach Candy Hospital is also great. The clinical quality, nursing staff and other features are better at Breach candy hospital when compared to Saifee, Hinduja Healthcare \&Bhatia hospital. By scoring above 8 in all the factors, Breach candy hospital is considered as the better performing hospital among the four.

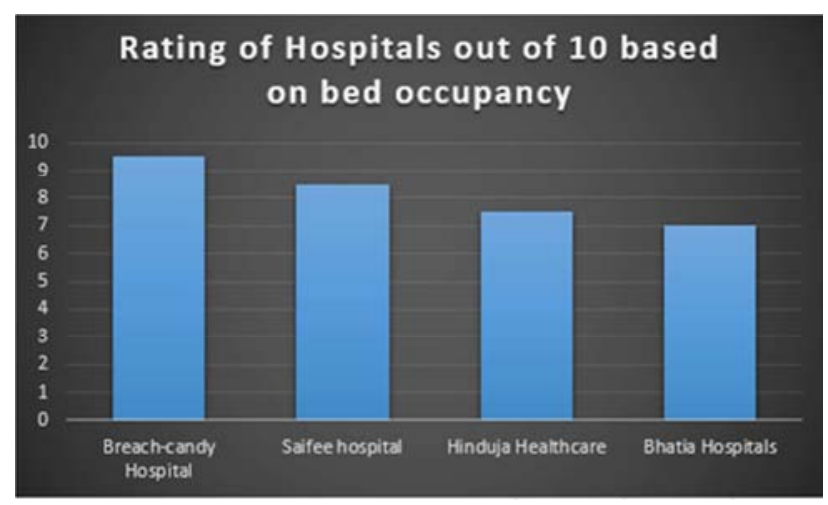

(Source: Excel).

Figure 7. Rating of hospitals based on bed capacity.

\section{Rating of hospitals out of 10 based on Nurse-to-patient staffing ratios}

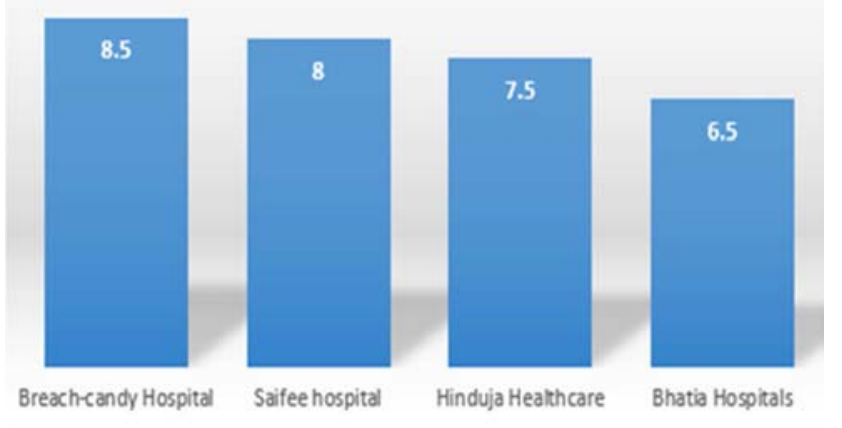

(Source: Excel).

Figure 8. Rating of hospitals based on staff ratio.

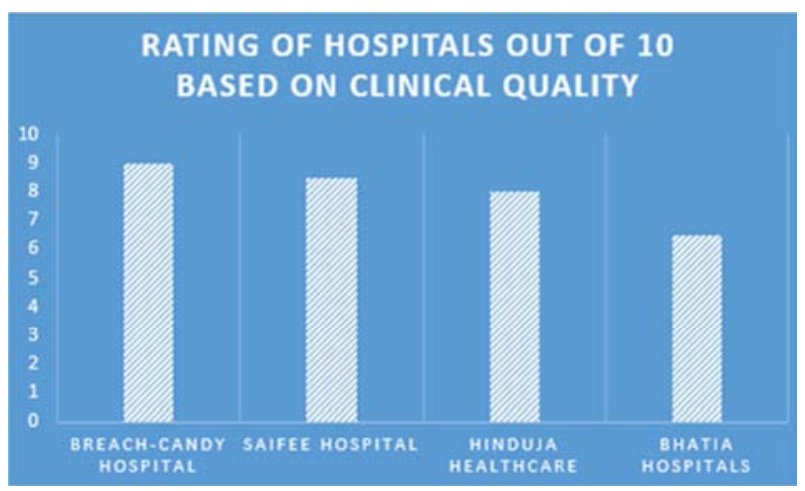

(Source: Excel).

Figure 9. Rating of hospitals based on clinical quality. 


\section{Rating of Hospitals out of 10 based on bed capacity}

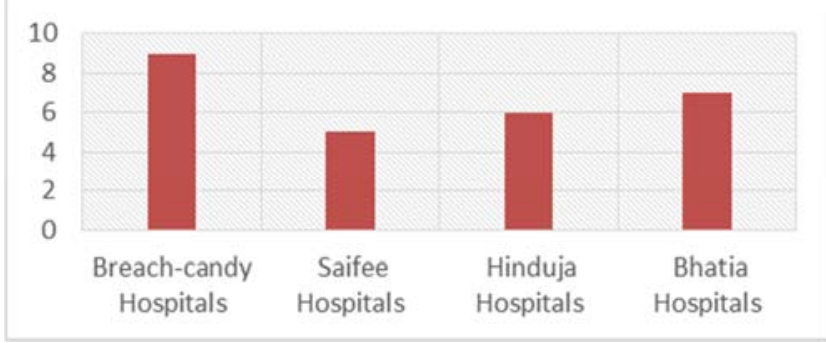

(Source: Excel).

Figure 10 Rating of hospitals based on treatment.

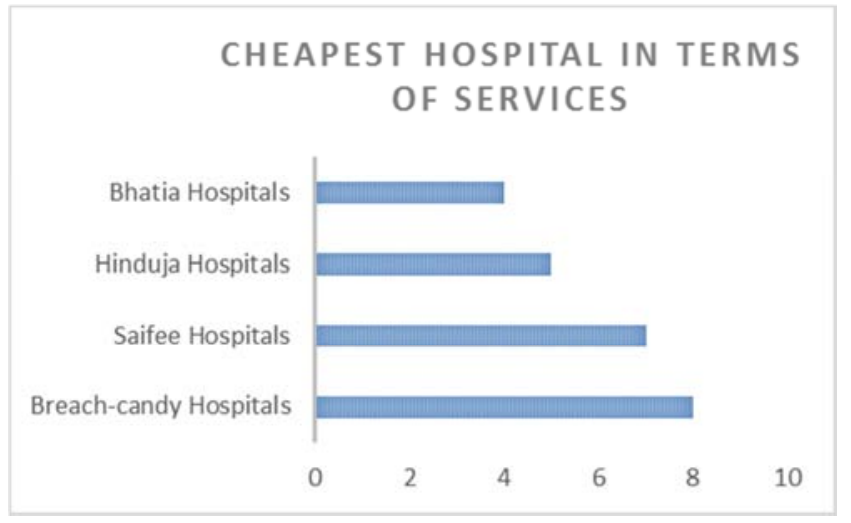

Figure 11. Rating of hospitals based on cost.

\section{Conclusion}

In this research paper, the primary focus was to develop a TQM\&5S implementation on which four hospitals will be measured. The measurement will help to evaluate the impact of TQM\&5S implementation model. In this part four hospitals have been taken into consideration which are "Breach candy hospital, Saifee Hospital, Bhatia Hospital, and Hinduja health care". As like hospitality industry there must be issues or challenges faced by the hospital management. Therefore by applying the concept of TQM\&5S, it will be easy to check the changes in terms of performance, quality, and customer satisfaction, due to the implementation of TQM\&5S. There will be some challenges that could be faced by the healthcare organization in the implementation of this model in the organizational structure. Discussions regarding these have been done in this paper. Those challenges can be overcome by applying TQM\&5S analysis and accordingly a survey sample of 63 has been taken to analyze and interpret and results are generated as shown in the above research work.

The evaluation is mainly based on the SERVQUAL model, which helps in assessing the customer's satisfaction by applying the modern method. From the analysis of four hospitals, the result clearly indicates that the application of TQM\&5s, has benefited the hospitals in terms of clinical quality, environment and others. Again, the Breach Candy
Hospital has shown the most superior service as compared to other chosen hospitals. Clear understanding of TQM\&5s can benefit the hospitals for improving their performance as well as quality of services. The performance level of Breach Candy Hospital is high followed by the Saifee Hospital. In the research paper, the results obtained from the implementation of TQM $\& 5 \mathrm{~s}$ have been discussed.

One can safely come to the conclusion that TQM\&5s implementation is definitely useful for the quality measurements of the Hospitals Performance so that future expansion plans can be planned accordingly.

\section{Appendices}

\section{Appendix 1: 5S in TQM}

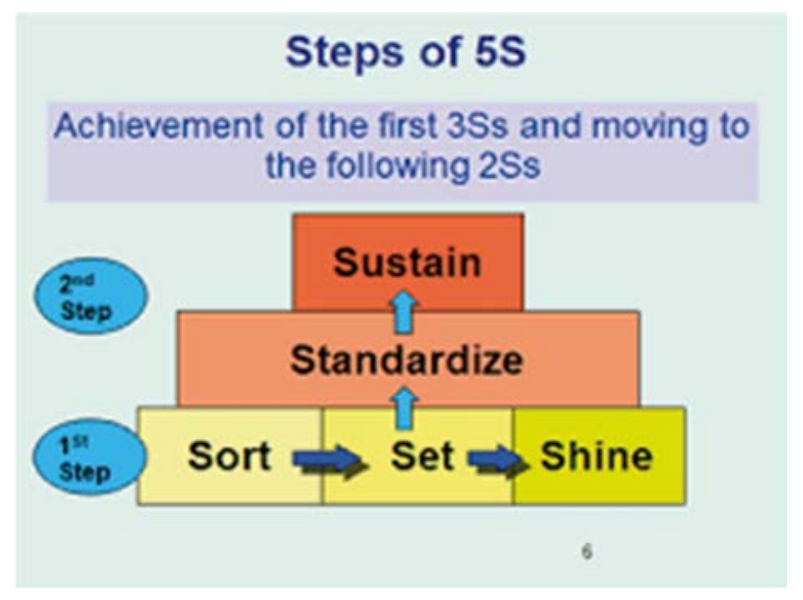

Figure A1. 5S in TQM.

(Source:

https://www.jica.go.jp/project/bangladesh/002/materials/ku57pq00001gtcssatt/Implementation_of_5S_in_Hospital-Setting.pdf).

\section{Appendix 2: TQM Movement in Health Care Industry}

\section{TQM Movement in HealthCare}

- Hospitals and other healthcare organization across the globe have been progressively implementing TQM to reduce costs, improve efficiency an provide high quality patient care.

- TQM, which places on improved customer satisfaction, offers the prospect of great market share and profitability.

- TQM can be an important part of hospitals competitive strategy in qualit. of healthcare system.

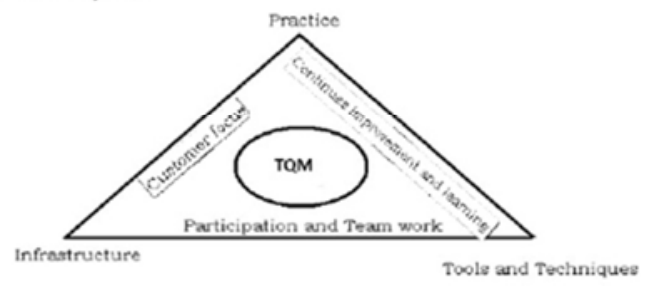

Figure A2. TQM Movement in Health Care.

(Source: https:/www.slideshare.net/ripjan/total-quality-management1470861). 


\section{Appendix 3: Questionnaire}

Q1. How do you rate the services of breach candy hospital?
Very unsatisfied
unsatisfied
neutral
satisfied
Very satisfied
2
13
15
25
8

Q2. How would you rate the clinical services offered by the doctors of Breach candy hospital?
Very unsatisfied
unsatisfied
neutral
satisfied
Very satisfied
4
1214
26
7

Q3. What do you feel about the customer support in the hospital?
Very unsatisfied
unsatisfied
neutral
satisfied
Very satisfied
1
821
20

Q4. What do you think about the clinical quality in breach candy hospital?
Very unsatisfied
unsatisfied
neutral
satisfied
Very satisfied
1
$11 \quad 17$
21
13

Q5. How do you rate the equipment and doctor support in this hospital?
Very unsatisfied
unsatisfied
neutral
satisfied
16
Very satisfied
4
$13-15$
15

Q6. Rating of Hospitals out of 10 based on Clinical quality
Bhatia Hospitals
Breach-candy Hospital
6.5
8.5
Saifee hospital
8
Hinduja Hospital
7.5

Q7. Rating of Hospitals out of 10 based on bed capacity
Bhatia Hospitals
Breach-candy Hospital
6.5
9
Saifee hospital
8
Hinduja Hospital
7

Q8. Rating of hospitals out of 10 based on Nurse-to-patient staffing ratios $\begin{array}{ll}\text { Bhatia Hospitals } & \text { Breach-candy Hospital } \\ 6.5 & 8.5\end{array}$
Saifee hospital 8
Hinduja Hospital

7
[5] Gupta, S. and Mukherjee, S., 2017. Determinants of Patient Satisfaction regarding Hospital Quality in West Bengal. International Journal of Research in Economics and Social Sciences (IJRESS), 7 (12).

\section{References}

[1] Abadi, I., Haming, M., Baharuddin, S. and Mahmud, A., 2018. A structural model of total quality management, kaizen, operational performance on service quality and patient satisfaction. Archives of Business Research, 6 (11).

[2] Alghamdi, M., Alomari, S., Althubaiti, M. and Aziz, A. A., 2017. A Review of TQM and EHR Focused Quality. nternational Advanced Research Journal in Science, Engineering and Technology, 4 (5).

[3] Balasubramanian, M., 2016. Total quality management $[\mathrm{TQM}]$ in the healthcare industry-challenges, barriers and implementation developing a framework for TQM implementation in a healthcare setup. Science Journal of Public Health, 4 (4), pp. 271-278.

[4] Farzadnia, E., Hosseini, Z. and Riahi, A., 2017. Study of hospital quality management and improvement rates in the hospitals. Journal of Humanities Insights, 1 (01), pp. 7-11.
[6] Rouf, M. A., Debnath, S. C., Haque, M. E., Chowdhury, Z. M. R., Hasan, D. M. M., Zannat, T. and Rabby, M. F., 2017. Quality of hospital services in 5S-KAIZEN-TQM implemented secondary level hospital: a cross-sectional study. Asian Journal of Medical and Biological Research, 3 (3), pp. 335-340.

[7] Utgjiu. ro, (2017), QUALITY IN HEALTH SERVICES MANAGEMENT, Available at: http://www.utgiiu.ro/revista/ec/pdf/2017-02/07_Cirnu.pdf [Accessed on 2.1.2020].

[8] Asq.org, (2019), Implementing TQM in hospital, Available at: http://asq.org/qic/display-item/index.html?item=12623 [Accessed on 2.1.2020].

[9] Saifeehospital.com, (2019), saifee hospital, Available at: https://www.saifeehospital.com/introduction.html [Accessed on 2.1.2020]. 
[10] Breach candy hospital.com (2020), breach candy hospital, Available https://www.breachcandyhospital.org/index.php/team[Accesse $\mathrm{d}$ on 10.2.2020].

[11] Breach candy hospital.com (2020), breach candy hospitalAvailable

https://www.breachcandyhospital.org/index.php/departments 1/ inisde-the-hospital[Accessed on 10.2. 2020].

[12] Breach candy hospital.com (2020), breach candy hospitalDoctors available

at: https://www.breachcandyhospital.org/index.php/doctors[Acce ssed on 10.2. 2020].
[13] Hinduja healthcare.com (2020), Hinduja Healthcare Surgical Available at https://www.hindujahealthcare.com/forpatients/new-facilities.html [Accessed on 12.2. 2020].

[14] Hinduja healthcare.com (2020), Hinduja Healthcare Surgical Departments available at https://www.hindujahealthcare.com/specialties/departments.as px[Accessed on 12.2. 2020].

[15] Saifee hospital.com 92020), saifee hospital-Clinical Specialties available https://www.saifeehospital.com/specialities.html [Accessed on 12.2. 2020]. 